\title{
Precise remote-monitoring technique of water volume and temperature of a crater lake in Aso volcano, Japan: implications for a sensitive window of a volcanic hydrothermal system
}

\author{
Akihiko Terada $^{1}$, Takeshi Hashimoto ${ }^{2}$, Tsuneomi Kagiyama ${ }^{1}$, and Hisashi Sasaki ${ }^{3}$ \\ ${ }^{1}$ Aso Volcanological Laboratory, Kyoto University, 5280 Kawayo, Minami-Aso, Kumamoto 869-1404, Japan \\ ${ }^{2}$ Institute of Seismology and Volcanology, Faculty of Science, Hokkaido University, \\ North 10 West 8, Kita-ku, Sapporo 060-0810, Japan \\ ${ }^{3}$ Kokusai Kogyo, Co. Ltd., North 7 West 7, Kita-ku, Sapporo 060-0807, Japan
}

(Received November 26, 2007; Revised January 30, 2008; Accepted February 8, 2008; Online published July 4, 2008)

\begin{abstract}
A high-resolution Digital Surface Model and a commercial digital camera have enabled precise and continuous monitoring of the crater lake at Aso volcano. From July 2006 onwards, infrared (IR) thermometry has been used with this system, enabling more accurate measurements of lake volume and temperature based on simple and intensive observations than has been possible in any other previous studies. The heat discharge remained largely constant at approximately $220 \mathrm{MW}$, with the exception of an abrupt increase to $280 \mathrm{MW}$ that coincided with a rapid decrease in the water level in August 2007. Simultaneously, an increase in temperature at a shallow depth was suggested by other observations. The crater lake was found to respond to even slight changes in volcanic fluid supply, which can be well quantified by our method. Thus, a crater lake can be monitored more precisely than subaerial fumaroles whose energy estimation is often accompanied by large uncertainties. Our monitoring technique of a crater lake provides information on the subsurface hydrothermal system beneath it, for which any in-situ measurements are practically impossible.
\end{abstract}

Key words: Crater lake, hydrothermal system, digital surface model, digital camera, Aso volcano.

\section{Introduction}

The water level and temperature of crater lakes on some volcanoes occasionally manifest interesting changes with time that are related to variations in volcanic activity (Hurst et al., 1991). Based on analyses of the chemistry, seismicity and heat-material budgets, some crater lakes, such as Poas volcano (Rowe et al., 1992), Kusatsu-Shirane volcano (Ohba et al., 1994), are considered to be constituent parts of a hydrothermal system. A laboratory experiment modeling the change in the water level of the Waimangu geothermal field suggested a hydrothermal instability (Vandemeulebrouck et al., 2005).

Nakadake in the Aso caldera (Fig. 1(a)) is one of the most active volcanoes in Japan, constantly emitting a large amount of volcanic gas, including 300-1000 × $10^{3} \mathrm{~kg} /$ day of $\mathrm{SO}_{2}$ (Monthly report by Japan Meteorological Agency, hereafter we call JMA). The crater of Nakadake has a hot crater lake, locally called Yudamari, which is over $200 \mathrm{~m}$ in diameter and has some fumaroles on its crater wall. In August 2007 the seismicity of the Aso volcano increased, and red hot glows associated with high-temperature gas emissions appeared at the fumaroles (Monthly report by JMA).

Observations made at Yudamari clearly demonstrate that the substantial changes in water level and temperature that

Copyright (c) The Society of Geomagnetism and Earth, Planetary and Space Sciences (SGEPSS); The Seismological Society of Japan; The Volcanological Society of Japan; The Geodetic Society of Japan; The Japanese Society for Planetary Sciences; TERRAPUB. have occurred are related to volcanic activities, as in the case of Poas (Brown et al., 1989; Rowe et al., 1992). Preceding an active period, the water level rapidly declines. The disappearance of lake water is followed by a red hot crater bottom or wall, then a phreatic to phreatomagmatic and strombolian eruption sequence over several months. Once the calm period of volcanic activity returns, the lake re-forms. The lake temperature is maintained at a level that is much higher than ambient temperature throughout most of the calm period (Ohsawa et al., 2003). These significant changes in the crater lake are probably caused by changes in volcanic fluid input to the crater bottom from depth. Thus, the precise monitoring of a crater lake should be capable of detecting variations in the hydrothermal system in the shallow part of the volcanic edifice.

Various geophysical observational studies, including seismicity (Yamamoto et al., 1999) and geomagnetic field (Tanaka, 1993), have been carried out with the aim of determining the ascent processes of the volcanic fluid or magma at Aso volcano. These have revealed that the sources are located at shallow depths below Yudamari. Although Yudamari is a constituent part of the upper end of a volcanic conduit, precise monitoring of the lake water based on hydrological and geothermal studies has not been performed. Any direct monitoring of the lake water at Yudamari is very difficult due to the steep topography, extreme low $\mathrm{pH}(<1)$ of the lake water and the high concentration of $\mathrm{SO}_{2}$ gas nearby.

Previous estimations of the lake volume had a large un- 

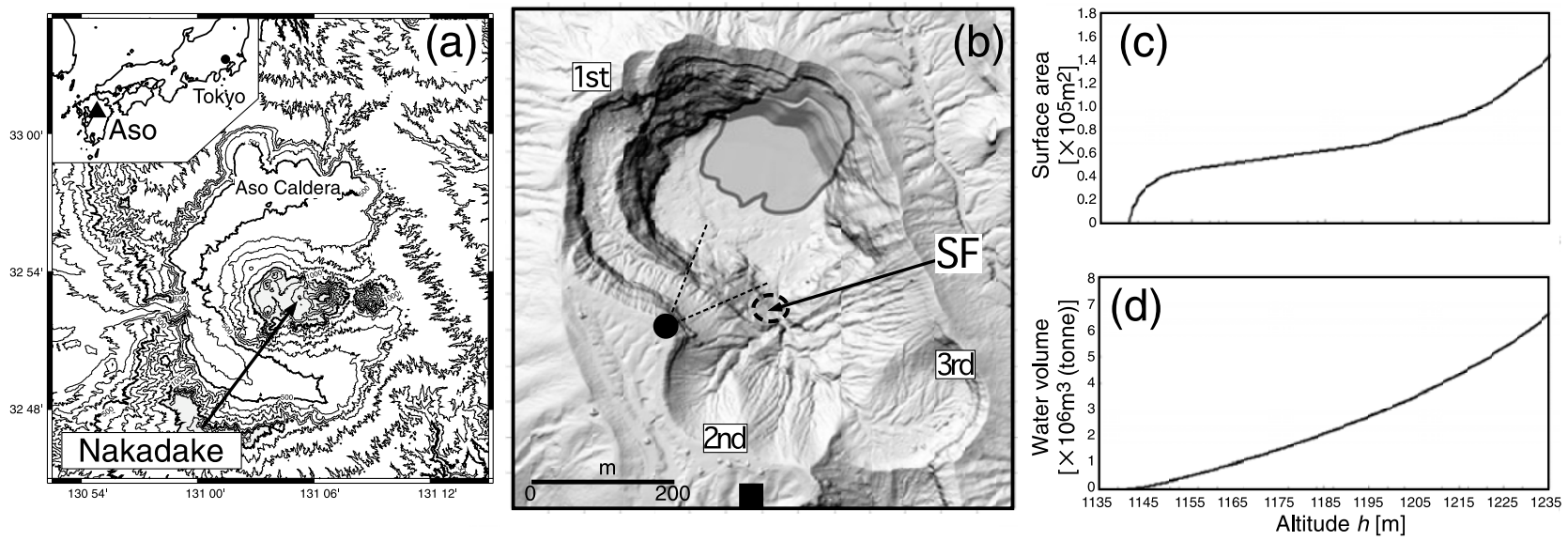

Fig. 1. (a) Locality of Nakadake, Aso volcano, Japan. (b) Shaded relief map around the craters of Nakadake produced from the DSM. The shaded area in the first crater was smoothly interpolated with the aid of a previous topography map (see text for details). Locality of the south-wall fumarole is indicated by SF. The automatic image recording system and a rain gauge are located at the closed circle and the square, respectively. (c) Surface area and (d) water volume as a function of water level calculated from the DSM (b).

certainty because there was a lack of precise data on the bathymetry of Yudamari and the crater topography above it. Accurate volume change data is necessary to determine a response to the precipitation input that is one of the important elements in the water budget of the lake. Errors in the lake surface area directly affect the estimation of evaporative water loss, which is also an important element in the heat budget of the lake. Therefore, a definitive topography is a critical key factor to a precise monitoring of the geothermal activity throughout the crater lake.

Although direct measurements are the most accurate way to monitor the lake, these are impossible to carry out in practical terms due to the inaccessibility mentioned above. In the study reported here, we used a high-resolution Digital Surface Model (DSM) that has detailed digital elevation data for topography to monitor the water volume changes as accurately as possible. A high-resolution commercial digital camera has been used to monitor changes in the water volume since July 2006. Combining these two methodologies with temperature measurements obtained with an infrared (IR) thermal imaging apparatus, we were able to determine slight but consistent changes in heat flow through Yudamari. During the study period, changes in volcanic activities around Yudamari were also confirmed from other geophysical observations. Here, we investigate the correlation between these phenomena and show how the results obtaining from monitoring a crater lake are useful for detecting subtle changes in the geothermal activities beneath it.

\section{Digital Surface Model of the Crater}

A 1-m-mesh DSM with an average accuracy of 10-30 cm was obtained from an airborne survey using a laser scanner (Wehr and Lohr, 1999) in April 2004, when most of the lake bottom was visible. The DSM provided us with an accurate relationship to calculate the surface and volume of the crater lake from water level data (Figs. 1(c), (d)).

Ground measurements were carried out in June 2007 to confirm the reliability of the DSM. Accurate positions of some artificial constructions obtained by our ground tri- angulation were compared with those represented on the DSM. This comparison confirmed that the DSM had a precision of several tens of centimeters in terms of positioning. The absolute elevation on the DSM was referenced to an adjacent leveling benchmark of the Geographical Survey Institute of Japan (GSI).

Using the DSM, we produced the shaded relief map shown in Fig. 1(b). Because the shaded area in Fig. 1(b) had originally some uncertainty due to the interruption of the laser beam by steam, it was smoothly interpolated by referring to the 1:5000 based topographic map published by GSI. The lowest level, $h_{0}$, of the crater bottom was $1141.25 \mathrm{~m}$ a.s.l. and corresponded to the altitude of the lake surface at the time the airborne measurement was carried out. We neglect the water remaining below $h_{0}$ in the calculation of lake volume in Fig. 1(d) because we are going to deal with the relative changes only for the period in which the lake level is much higher than $h_{0}$.

\section{Observations of Yudamari Crater Lake \\ 3.1 Water level}

To detect subtle changes in the surface area and volume of the crater lake using the DSM, we first made a precise measurement of the water level $h$ because the water level is much easier to measure accurately than surface area or lake volume. In order to monitor the lake water level conveniently, we have developed an automatic image recording system (Fig. 2(a)) consisting of a commercial compact digital camera (CASIO QV-R4) that automatically records photographs at a time interval of 20-30 min. Our system provides high-resolution images of the crater lake, such as shown in Fig. 2(b). Resolution of the images was $2304 \times 1712$ pixels, which corresponds to approximately $10-20 \mathrm{~cm} /$ pixel in the area of particular interest (i.e., lake margin).

To obtain $h$ with an accuracy of $10-20 \mathrm{~cm}$ in an actual scale from the automatically recorded photographs (Fig. 2(b)), a number of specific wall rocks (such as those indicated by a black arrow in Fig. 2(b)), whose positions had been accurately measured by triangulation, were used 

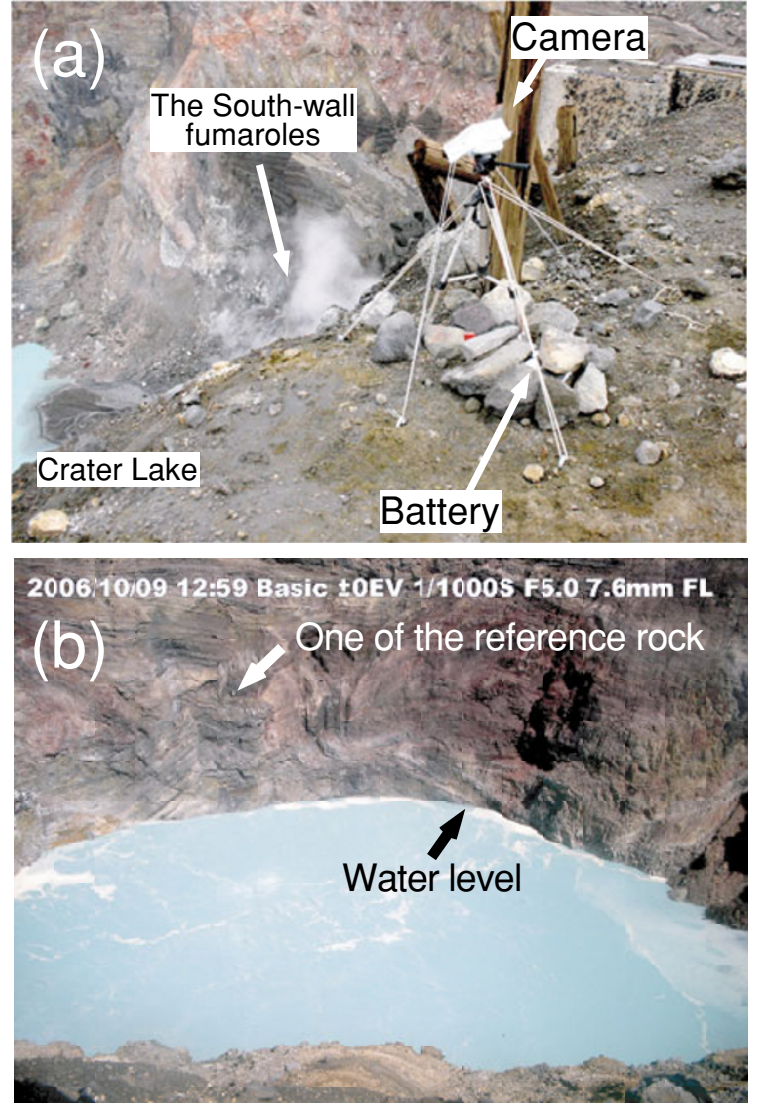

Fig. 2. (a) The automatic image recording system in operation at the crater rim site (Fig. 1(b)). Seen at the left is the south end of the crater lake (Fig. 1(b)). (b) An example of the photograph taken by the system (Fig. 2(a)). The white arrow indicates one of the rocks with a remarkable pattern that was used as a level reference.

as reference points.

\subsection{Lake surface temperatures}

The temperature of the lake surface has been regularly measured from the crater rim by JMA for over 10 years using an IR thermometer. The temperature measured by an IR thermometer is, however, usually lower than the actual temperature due to the absorption effect by water vapor. To overcome this problem, we calibrated JMA's data with an occasional in-situ temperature measurement of the lake in July 2007. It should be noted that such an in-situ measurement cannot be performed frequently because it requires a substantial amount of effort to first put thermometers into the crater lake and to subsequently recover them.

This direct measurement revealed that water temperatures at 10 and $100 \mathrm{~cm}$ below the lake surface are uniform, showing a higher value by $8 \mathrm{~K}$ than a simultaneous measurement with the IR thermometer. We assume here a difference of $6 \mathrm{~K}$ between the temperature determined by the IR thermometer and the in-situ temperature, taking into consideration the skin effect (slight decrease of water temperature in a boundary layer at the very surface of the lake; Oppenheimer, 1997) based on the wind velocity at the Aso Weather Station (AWS; operated by JMA) located at approximately $1.2 \mathrm{~km}$ west of the first crater. Using this procedure, we obtained the temporal change in the lake surface temperature shown in Fig. 3(d). The tempera- tures in Fig. 3(d) show a variable amount of scattering. In most cases, we believe that atmospheric conditions, such as steam interruption, affected the temperature measured by the IR camera.

\subsection{Precipitation}

Precipitation data around the crater lake are available from a rain gauge that was installed at approximately $50 \mathrm{~m}$ south of the second crater rim in July 2007 (Fig. 1(b)). The precipitation of the period before July 2007 was evaluated based on measurements obtained with a rain gauge of the same model that was simultaneously functional at AWS.

The simultaneous precipitation observations revealed that the precipitation at the crater lake side has similar trend but is 1.1 -fold more than that at AWS. Hence, the daily precipitation of the crater lake before July 2007 is estimated from AWS's data multiplied by 1.1 .

\section{Results}

\subsection{Changes in Yudamari crater lake}

The changes in the water level and volume of the crater lake are shown in Figs. 3(a) and (b), respectively. We measured water level once a day because we found water level changes were generally slow, with the exception of periods of heavy rains. On the other hand, the crater was often filled with steam for several days, particularly during the winter and rainy seasons. In general, therefore, water level was measured at least once a week.

Figure 3 shows some episodic rapid increases in water volume (gray arrows) coinciding with rainy seasons, mild increasing trends in late 2006 (black arrows A and B), a plateauing (black arrow $\mathrm{C}$ ) and gradual periods of decreasing volume (black arrows D and E).

To evaluate the water inflow from precipitation, we compared the change in the water volume of the carter lake with precipitation. The results of this comparison are given in Fig. 4. We selected here "heavy rainfalls" to be those in which over $100 \mathrm{~mm}$ rainfall fell within 1 week. Over a short time scale, the background change in water volume caused by evaporation, seepage and volcanic input is much less than the changes in volume caused by heavy rainfalls.

This simple analysis shows a linear relationship between precipitation and water volume change (Fig. 4). Resolution of the water volume estimation is limited to $5 \times 10^{3} \mathrm{~m}^{3}$, as shown by error bars. The rather scattered data is probably due to the differences in precipitation intensity from event to event. We evaluated here an empirical precipitation inflow rate of $1.1 \times 10^{5} \mathrm{~kg} / \mathrm{mm}$, which corresponds to an equivalent catchment area of $1.1 \times 10^{5} \mathrm{~m}^{2}$.

Based on the precipitation data and this empirical relation, we estimated cumulative precipitation input as shown in Fig. 3(c). The episodic sharp increases in lake volume (gray arrows in Fig. 3(b)) are well replicated by heavy rainfall events that can be seen in Fig. 3(c). However, it is noted that gradual changes in volume during the periods $\mathrm{A}$ to $\mathrm{E}$ do not show a direct correlation with precipitation.

\subsection{Heat discharge rate}

Most of the thermal energy is generally discharged from a hot crater lake by evaporative, sensible heat and radiative fluxes from the lake surface. To estimate the these heat fluxes, we applied the model of Ryan et al. (1974), which 

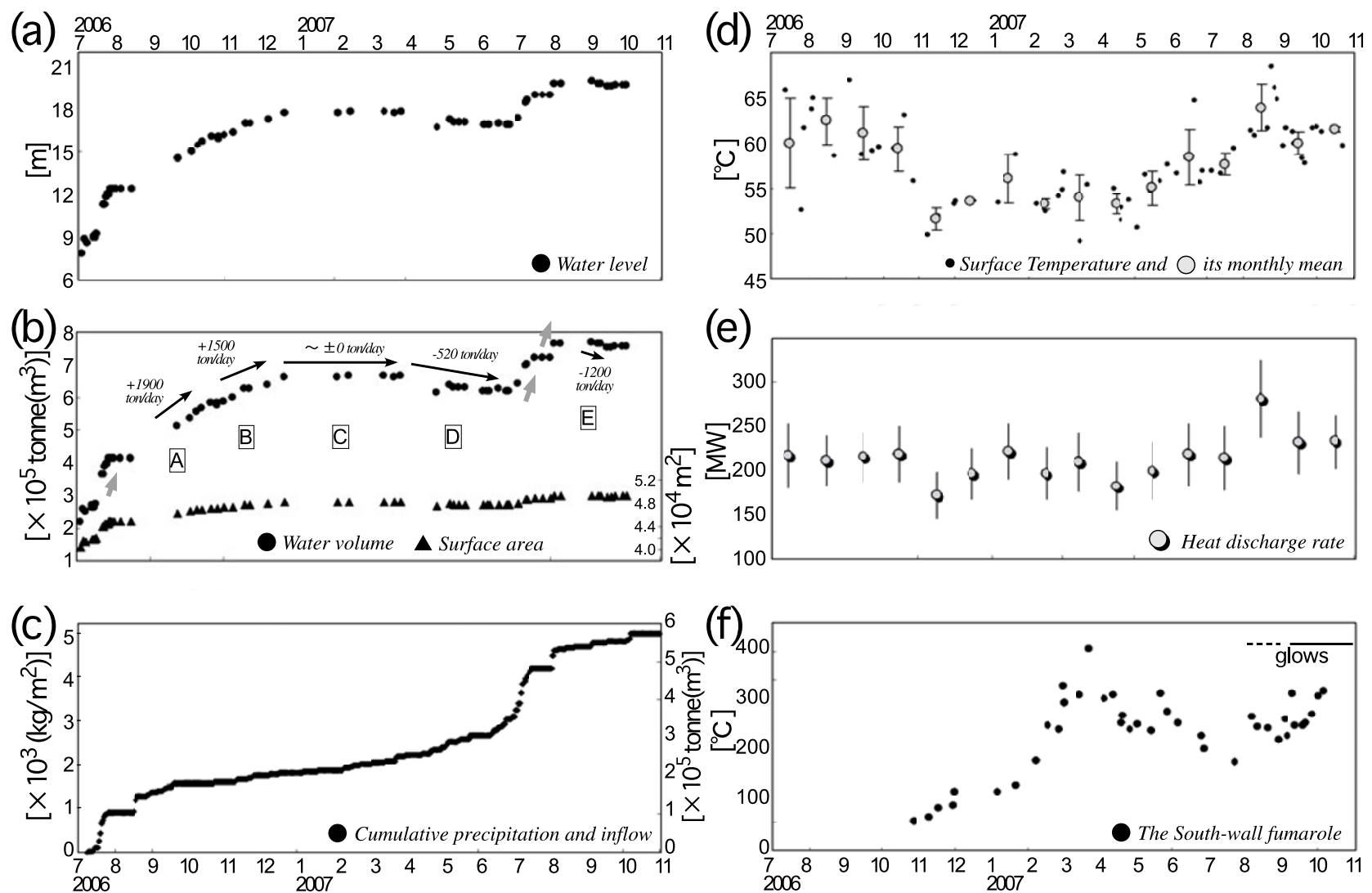

Fig. 3. (a) Water level and (b) water mass (volume) and surface area of Yudamari crater lake. (c) Cumulative precipitation and cumulative income due to precipitation, the equivalent catchment area of $1.1 \times 10^{5} \mathrm{~m}^{2}$ is taken into account (see text for details). (d) Temperature of the lake surface measured by JMA's IR thermometry. Small dots represent each measurement, whereas the gray circles repesent monthly means with the square root of the standard deviations. (e) Computed monthly mean heat discharge rate from the lake surface. (f) Temperature of the south-wall fumaroles measured by JMA's IR thermometry.

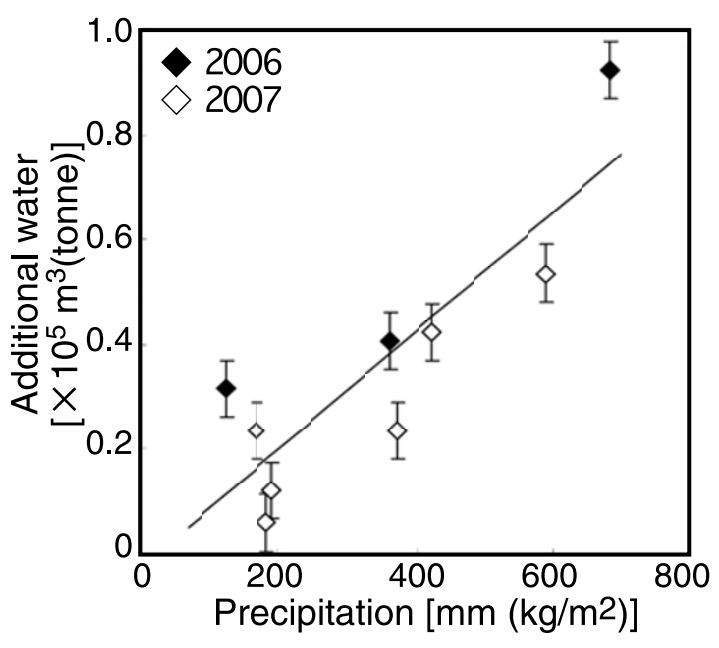

Fig. 4. Relationship between water volume change and precipitation, for periods with over $100 \mathrm{~mm}$ rainfall per week, derived from Figs. 3(b) and 3(c). The solid line is the linear regression.

includes the effects of free and forced convections. The model requires data on the surface area and temperature of the lake, air temperature, humidity and wind velocity at $2 \mathrm{~m}$ above the lake surface. We use the monthly mean air temperature and humidity at AWS because the altitude of AWS is almost the same as that of the crater lake surface. As forced convection is a sensitive function of wind velocity, the factor of actual wind velocity in the crater has to be applied with care. Effective wind velocity on the lake seems to be systematically reduced by the sheltered topography (Fig. 1). In this study, the heat discharge rate was calculated using $75 \%$ of the monthly-mean wind velocity at AWS as the most probable value. We assessed the estimation errors using 100 and $50 \%$ of the wind speed at AWS as maximal and minimal limits, respectively.

Figure 3(e) shows the heat discharged by evaporation, sensible heat and radiation from the crater lake. The heat discharge shows an almost constant rate of approximately 220 MW, although the monthly lake area (Fig. 3(b)), lake temperature (Fig. 3(d)), air temperature and wind velocity show substantial variations. These results suggest some feedback effect by the crater lake, such as an increase in the heat discharge rate due to a decrease in air temperature leading to a cooling of the lake water and, consequently, the maintenance of the heat discharge rate.

Using this model (Ryan et al., 1974), we estimated the mass loss rate by evaporation to be $70 \mathrm{~kg} / \mathrm{s}$. Thus, $3 \times 10^{6}$ tonne of water escaped from the lake surface during a 15 month period.

In August 2007, the heat discharge rate suddenly rose to $280 \mathrm{MW}$; consequently, the water volume turned into a decreasing trend. 


\section{Discussion}

Using the DSM and a digital camera, our intensive observation with a newly developed monitoring system has successfully revealed the volume changes much more accurately than any previous measurements.

\subsection{Sensitivity of the crater lake to geothermal activi- ties}

The variations in the crater lake seem to be correlated with other observed changes. In periods $\mathrm{A}$ and $\mathrm{B}$, water volume increased, while volcanic activities were relatively calm. In period $\mathrm{C}$, the increase of the water volume stopped, while the temperature of the south-wall fumaroles (Fig. 1(b)) rose (Fig. 3(f)). Simultaneously, changes in geomagnetic field were observed (M. Utsugi, personal communication, 2007). Generally, as temperature increases, rocks lose their magnetization. Geomagnetic field changes following period $\mathrm{C}$ imply that thermal demagnetization occurred at a shallow depth. In period D, the water volume decreased slowly. The elevated temperature of the south-wall fumaroles and the thermal demagnetization lasted throughout this period. In period E, the heat discharge rate suddenly rose to a consistent level of $280 \mathrm{MW}$, and the water volume decreased rapidly relative to period D. Simultaneously, the red hot vents were visible by eye at night at the south-wall fumaroles (based on the Monthly report of JMA).

If the enthalpy of the input volcanic fluid increases, evaporation must be enhanced as water temperature rises, which results in a decrease of water volume. At Aso's crater lake, we suspect that a decrease in water volume in the period $\mathrm{E}$ was caused by a slight increase in the enthalpy of the input volcanic fluid. In the period $\mathrm{E}$, heating at a shallow depth is also suggested by observation of the red-hot crater wall accompanying the temperature rise at the south-wall fumaroles and by substantial change in the geomagnetic field due to thermal demagnetization. We did not estimate the seepage water flux from lake bottom in our study. However, based on Darcy's law, we believe that this water flux depends only on the bottom area and the mean depth of lake. Our observations suggest that neither of these changed during period $\mathrm{E}$.

A crater lake manifests observable changes in its level and temperature, reflecting the thermal activity at the crater bottom, whereas the evaluation of the energy emitted by subaerial fumaroles or steaming ground has large uncertainties, particularly when a remote sensing apparatus (Oppenheimer and McGonigle, 2004) or image analysis (Kagiyama, 1981) are applied rather than in-situ measurements. Consequently, comparisons of slight changes of geothermal activity and other heat budget calculations are often unreliable. At crater lakes such as that of the Aso volcano, most of the thermal energy and mass that is injected into the lake bottom is trapped in the lake water. Consequently, we can detect even slight changes from a precise monitoring of a crater lake.

\subsection{Implication for the volcanic hydrothermal system}

Previous geomagnetic observations revealed that rapid heating/cooling occurred at depths of several hundred meters during the latest eruptive period from 1989 through 1990 (Tanaka, 1993). Recent magnetotelluric surveys have detected a significantly low resistivity region at approxi- mately $200 \mathrm{~m}$ below the crater lake. An analysis of the longperiod tremor indicated that volcanic fluid is transported to the region through a crack-like conduit (Yamamoto et al., 1999). These results suggest that a hydrothermal system exists at a shallow depth (Kanda et al., in press).

It is most likely is that volcanic fluid input to the crater bottom is mainly supplied from the inferred hydrothermal system. Based on the magnetotelluric results, the source of the geomagnetic field changes in periods $\mathrm{D}$ and $\mathrm{E}$ is located around the hydrothermal system. We therefore suspect that the physical parameters, such as temperature and pressure of the hydrothermal system, are-directly and/or indirectly-reflected by the state of Yudamari. The precise monitoring of the crater lake may constrain the mechanism of volcanic fluid transfer at the shallow depth.

The volume of the lake has increased since July 2006 by approximately $7 \times 10^{5}$ tonne (Fig. 1(b)). The collected precipitation of $5.5 \times 10^{5}$ tonne (Fig. 3(c)) could roughly explain this amount. However, it cannot explain at all the extra volume loss of $3 \times 10^{6}$ tonne by evaporation, which is an order of magnitude larger. We consider that the lake water inflow has been obtained mainly by inflow at the lake bottom.

We suspect that the bottom input may include meteoric supply with a time delay. Lake water that has seeped from the lake is partially recycled into the hydrothermal system, recharging the lake (Ohsawa et al., 2003). Further continuous observation with our system and a more detailed budget study will enable us to evaluate the mass and enthalpy of the volcanic fluid supply from the hydrothermal system and to monitor their variations in time.

Acknowledgments. We are very grateful to the staff of Aso Weather Station, Japan Meteorological Agency for sharing their data with us and giving us permission to publish them. We thank Yasuaki Sudo and Shin Yoshikawa for their helpful discussions and constructive criticisms. We are indebted to Yasuo Miyabuchi for the precipitation observation. Thanks also go to Shinji Ohsawa, Takeshi Saito and Mitsuru Utsugi for their valuable comments. Constructive reviews by Takeshi Ohba and Tony Hurst have substantially improved the manuscript. This work was supported by Kyoto University Active Geosphere Investigations for the 21st Century Centers of Excellence Program (KAGI21), which was approved by the Ministry of Education, Culture, Sports, Science, and Technology (MEXT) of Japan.

\section{References}

Brown, H., H. Rymer, J. Dowden, P. Kapadia, D. Stevenson, J. Barquero, and L. D. Morales, Energy budget analysis for Poas crater lake: implication for predicting volcanic activity, Nature, 339, 370-373, 1989.

Hurst, A. W., H. M. Bibby, B. J. Scott, and M. J. J. McGuinness, The heat source of Ruapehu crater lake; deductions from the energy and mass balances, J. Volcanol. Geotherm. Res., 46, 1-20, 1991.

Kagiyama, T., Evaluation methods of heat discharge and their applications to the major active volcanoes in Japan, J. Volcanol. Geotherm. Res., 9, 87-97, 1981.

Kanda, W., Y. Tanaka, M. Utsugi, S. Takakura, T. Hashimoto, and H. Inoue, A preparation zone for volcanic explosions beneath Naka-dake crater, Aso volcano as inferred from electrical resistivity surveys, $J$. Volcanol. Geotherm. Res., (in press).

Ohba, T., J. Hirabayashi, and K. Nogami, Water, heat and chloride budgets of the crater lake Yugama at Kusatsu-Shirane Volcano, Japan, Geochem. J., 28, 217-231, 1994.

Ohsawa, S., Y. Sudo, H. Mawatari, G. Shimoda, M. Utsugi, K. Amita, S. Yoshikawa, M. Yamada, K. Iwakura, and Y. Onda, Some geochemical features of Yudamari Crater Lake, Aso volcano, Japan, Geotherm. Res. 
Rep. Kуиsуu Univ., 12, 62-65, 2003 (in Japanese with English abstract). Oppenheimer, C., Ramifications of the skin effect for crater lake heat budget analysis, J. Volcanol. Geotherm. Res., 75, 159-165, 1997.

Oppenheimer, C. and A. J. S. McGonigle, Exploiting ground-based optical sensing technologies for volcanic gas surveillance, Ann. Geophys., 47, 1455-1470, 2004.

Rowe, G. L., S. L. Brantley, M. Fernandez, J. F. Fernandez, A. Borgia, and J. Barquero, Fluid-volcano interaction in an active stratovolcano; the crater lake system of Poas Volcano, Costa Rica, J. Volcanol. Geotherm. Res., 49, 23-51, 1992.

Ryan, P. J., D. R. Harleman, and K. D. Stolzenb, Surface heat loss from cooling ponds, Water Resour. Res., 10, 930-938, 1974.

Tanaka, Y., Eruption mechanism as inferred from geomagnetic changes with special attention to the 1989-1990 activity of Aso Volcano, J.
Volcanol. Geotherm. Res., 56, 319-338, 1993.

Vandemeulebrouck, J., D. Stemmelen, T. Hurst, and J. Grangeon, Analogue modeling of instabilities in crater lake hydrothermal systems, $J$. Geophys. Res., 110, doi:10.1029/2003JB002794, 2005.

Wehr, A. and U. Lohr, Airbone laser scanning - an introduction and overview, ISPRS J. Photogrammetry Remote Sensing, 54, 68-82, 1999.

Yamamoto, M., H. Kawakatsu, S. Kaneshima, T. Mori, T. Tsutsui, Y. Sudo, and Y. Morita, Detection of a crack-like conduit beneath the active crater at Aso Volcano, Japan, Geophys. Res. Lett., 26, 3677-3680, 1999.

A. Terada (e-mail: terada@aso.vgs.kyoto-u.ac.jp), T. Hashimoto, T. Kagiyama, and H. Sasaki 